\title{
Influence of Super plasticizer on the Compressive Strength and Setting Time of Concrete
}

\author{
Akaolisa Celestine Ezeagu, Ezeagu Ebuka Edwin \\ Department of Civil Engineering, Faculty of Engineering, Nnamdi Azikiwe University, Awka, Nigeria \\ Email address: \\ ac.ezeagu@unizik.edu.ng (A. C. Ezeagu) \\ To cite this article: \\ Akaolisa Celestine Ezeagu, Ezeagu Ebuka Edwin. Influence of Super plasticizer on the Compressive Strength and Setting Time of Concrete. \\ American Journal of Engineering and Technology Management. Vol. 6, No. 5, 2021, pp. 82-88. doi: 10.11648/j.ajetm.20210605.12
}

Received: September 13, 2021; Accepted: October 4, 2021; Published: October 28, 2021

\begin{abstract}
Super plasticizer or High range water reducer is a specific type of admixture that is used to produce low watercement ratio high strength concrete with normal or enhanced workability. Therefore by using Super plasticizers, it became easier for contractors nowadays to place highly workable, durable, pump able concrete with higher strength, and even with less cost than using other ways to produce concrete with such properties. The effects of SPs on physical properties of hardened and fresh concrete is therefore studied in this research work by considering $1 \%, 2 \%, 3 \%$ and $4 \%$ of two types of Super plasticizers namely Conplast 430 and Dr Fixit which was referred as SP A and SP B respectively in this research. A mix ratio of 1:2:4 was used with a constant 0.5 water-cement ratio in order to determine the effect of SP on workability. A set of 72 nos of $150 \mathrm{~mm} \mathrm{x}$ $150 \mathrm{~mm} \times 150 \mathrm{~mm}$ concrete cubes specimens were casted and cured by complete immersion in water. Setting time test was carried out to determine the rate at which concrete hardens. The samples were further tested for compressive strengths at the ends of 7, 14, 21 and 28 days of curing. The result showed that the highest compressive strength for Conplast-430 (SP A) at 7 days was achieved at $1 \%, 14$ days at $2 \%, 21$ days at $2 \%$ and that of 28 days was achieved at $2 \%$. While the highest compressive strength for Dr Fixit (SP B) at 7 days was achieved at 1\%, 14 days at 1\%, 21 days at $1 \%$ and that of 28 days was achieved at $3 \%$. This therefore shows that use of super plasticizer has increased concrete strength and on time even at very low percentage introduction by volume.
\end{abstract}

Keywords: Dosage, Harden, Setting Time, Strength and Super plasticizer

\section{Introduction}

Concrete is the most commonly used material for building and civil engineering constructions in the world. Concrete as the most widely used man-made construction materials is second only to water as the most utilized substance on earth. [9]. It is basically composed of two components: paste and aggregate. The paste, which binds the aggregate together, contains cement and water and sometimes other admixtures (e.g Super plasticizers), whereas the aggregate contains sand and gravel or crushed stone. The aggregates are relatively inert filler materials which occupy 60 to $75 \%$ of the concrete volume and can therefore be expected to have influence on its properties [7, 6]. The workability of the different aggregate sizes at the same water-cement ratio of 0.5 decreases as the aggregate size increases [11]. It has been established that Salt water reduces the strength of concrete and can possibly lead to corrosion of reinforcement in certain cases but not of super plasticizers [6].

The word concrete comes from a Latin word concretus which means to grow together which implies that it is a composite of different materials. It is composed of coarse granular material called aggregate or filler which is embedded in a hard matrix of material (cement or binder with water) binding the aggregates together and filling the space formed between them. When the constituents are mixed with water the concrete solidifies and hardens due to a chemical reaction between the water and the cement called hydration, which finally forms a stone like material by binding the aggregates together. Ezeagu et al studied the effect of alkali of sodium hydroxide on concrete using mortal-bars and found out the total softening and expansion of the concrete mortal bars as a result of alkaline solution [4] thus portrays danger of concrete disintegration due to alkalis. Concrete develops an average of $26 \%$ of the 28 days strength in 1 day and $85 \%$ in 21 days and equally develops strength rapidly at 
early age compared to later ages [10]. Prior to discussing super plasticizer and its performance in concrete, some of the literatures on admixtures and additives are reviewed to properly understand the differences between them. An admixture, according to the ASTM C-125-97a standards, is a material other than water, aggregates or hydraulic cement that is used as an ingredient of concrete or mortar, and is added to the batch immediately before or during mixing. Ganiron defined admixture as a material other than water, aggregate or hydraulic cement that is used as an ingredient of concrete or mortar, and is added to the batch immediately before or during mixing [8]. Neville and Brooks argued that admixture refers to a substance which is added at the cement manufacturing stage [11]. Admixtures are however, used in concrete to improve or modify some or several properties of Portland cement concrete or to compensate for some deficiencies [12]. Cements contain three basic ingredients.

1. Portland cements for higher strength and increase setting time.

2. Plasticizers, such as finely ground limestone or lime hydrate for increased workability.

3. Air -entraining additives for greater durability and workability. Masonry cement mortars are pre-blended and prepackaged in bags. Each bag is mixed with a specified volume of fine aggregate (sand) to meet certain minimum physical requirements. Consequently, masonry cement mortars provide consistency of mixture during construction. Furthermore, masonry cement mortars provide excellent workability along with adequate bond and good compressive strength (1).

Cement additives are used to bring special properties to the fresh or hardened concrete; these special properties are related to the reduction of water consumption, increased resistance to compression or extension of the setting time, and others, they also can improve the durability, workability and strength of a concrete mixture and also is used to overcome difficult situations construction such as casts in hot or cold weather, pumping requirements, early strength requirements or specifications of a water/cement ratio very low [14]. Grinding assistants are the most common additives for cement and they can consist of glycols, alkanolamines and phenolic compound sand can be tentatively qualified according to the properties that they modify in fresh or harden concrete.

Generally, admixtures are used for the following purposes [7]: to retard the initial setting of concrete, to increase the strength of concrete, to improve the workability of fresh concrete, to improve the durability of concrete, to reduce the heat of evaluation, to control the alkali aggregate expansion, to promote pozzolanic properties in concrete, to aid in curing of concrete, to promote wear resistance to concrete, to reduce shrinkage during setting of concrete, to reduce bleeding of concrete, to impart colour to concrete, to aerate concrete or mortar to produce light weight concrete, to reduce segregation in grout mixes, to produce fungal, insects, etc. resistant concrete, to produce non skid surface concrete, to increase resistance to chemical attack, to decrease the permeability of concrete, to check the corrosion of concrete reinforcement and to increase the bond between the old and new surface and also between concrete and reinforcement. Admixtures help to manipulate a freshly mixed quantity concrete with minimum loss of homogeneity (uniform) [4, 15]. The primary aim of this project is to investigate the effects of a locally available super plasticizer on concrete, which will involve the compressive test on concrete. Therefore, this experimental research aims to study the effect of any super plasticizer which is locally available on the workability and strength of concrete. The objectives of this study are to; determine the effect of super plasticizer on the workability of M15 grade concrete, determine the effect of super plasticizer on the setting time of concrete, determine the effect of super plasticizer on the compressive strength of M15 grade concrete, determine the of optimum dosage for each super plasticizer in terms of workability and compressive strength of M15 grade concrete.

\section{Materials and Methods}

Concrete is a composite of cement, aggregate (fine and coarse) and water. Sometimes, chemical or mineral admixtures are added in order to change the characteristics of concrete for certain applications. Since the materials are important in determining the quality of produced concrete, they should be properly selected and chosen before the beginning of the experiment.

1. Coarse Aggregate: The coarse aggregate used was crushed granite $(20 \mathrm{~mm}$ maximum size and retained on a $10 \mathrm{~mm}$ sieve). They were gotten from Abakiliki and bought from retailers in Eke Awka.

2. Fine Aggregate: The fine aggregate used was dry river sand from Trans Ekulu river. The range of sizes of fine aggregate was from 600 micron $-4.75 \mathrm{~m}$ on the BS test sieve. The sieve was used to remove larger aggregate sizes and impurities.

3. Portland Limestone Cement (PLC): The brand of Portland cement used was Dangote cement. The cement brand complied with the requirements of BS EN (1995) and was obtained from local dealers in Awka, Anambra state. The grade of the cement is $42.5 \mathrm{R}$.

4. Water: Portable water gotten from the school laboratory was used throughout the research. The quality of water conformedto the specification of BS 1008, (2002) which specifies that water to be used must be safe for drinking, free from odour, colour, taste and impurities, thus satisfying the specification requirement for water to be used for concrete production.

5. Super plasticizer: The SP used in this study, because of its availability, were Conplast-430 was locally produced at FOSROC laboratory in Enugu and Dr Fixit, purchased from the market for comparison and they complied with ASTM C494 Type D \& G and BS 5075 requirements for high range water-reducing admixtures. 


\section{Mixing Procedures}

As obtained from the mix calculations by weight, $6 \mathrm{~kg}$ of cement was weighed out and mixed with $12 \mathrm{~kg}$ of fine aggregate (sand) by hand until an even mix was obtained. Thereafter, $27 \mathrm{~kg}$ of gravel was weighed out and added to the cement and sand mixture and water of $3 \mathrm{~kg}$ (in conformity with a 0.5 water/cement ratio) was gradually added to the mixture. The mixture was gradually stirred as the water was added to bring about an even concrete paste. Samples with different dosages of super plasticizer were prepared, while other samples were prepared without adding super plasticizer, in order to use as a control samples.

The dosages used for Dr Fixit were: 1\%, 2\%, 3\%, 4\% and that of Conplast 430 were: $1 \%, 2 \%, 3 \%, 4 \%$ by weight of cement. In this research Conplast 430 will be termed $S P A$ while Dr Fixit will be referred as $S P B$.

The preparation of the concrete samples and assessed was carried out in accordance to the appropriate British Standard such as BS 1881 (1986), BS 1881 (1988) and BS 812 (1990).

Table 1. Concrete mix ratio with super plasticizers SPA and SPB ratios.

\begin{tabular}{llll}
\hline Concrete mix & Water Cement Ratio & Super plasticizer Dosage (SPA) (\%) & Super plasticizer Dosage (SP B) (\%) \\
\hline 1 & 0.5 & 0.0 & 0.0 \\
2 & 0.5 & 1.0 & 1.0 \\
3 & 0.5 & 2.0 & 2.0 \\
4 & 0.5 & 3.0 & 3.0 \\
5 & 0.5 & 4.0 & 4.0 \\
\hline
\end{tabular}

\section{Results and Discussion}

\subsection{Super Plasticizer Effect on Slump Test}

Workability is one of the main properties of fresh concrete, therefore, slump tests were conducted for the concrete mixes with different superplasticizer dosages, in order to measure this property. The results for slump loss of super plasticized concrete summarized in the table below. The data of dimension, SP ratio in percentage and slump in $\mathrm{mm}$ were recorded. It showed a relation between dosages of SP and slump loss. And then, the value of slump loss at different specific dosages of SPs is then plotted in figure 1.

Table 2. Concrete mix ratios slump tests for SPA and SPB plasticizers.

\begin{tabular}{llll}
\hline Concrete Mix & SP Dosages (\%) & Slump Loss (mm) (SP A) & Slump Loss (mm) (SP B) \\
\hline 1 & 0.0 & 45 & 45 \\
2 & 1.0 & 120 & 48 \\
3 & 2.0 & 135 & 92 \\
4 & 3.0 & 145 & 155 \\
5 & 4.0 & 160 & 175 \\
\hline
\end{tabular}

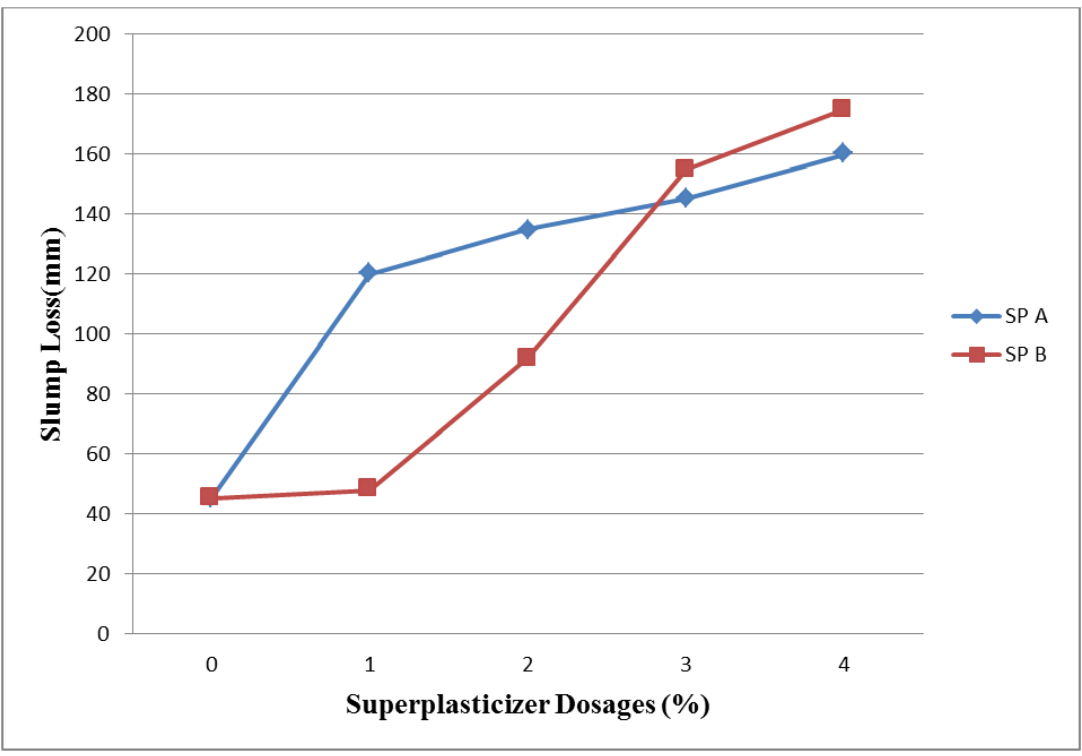

Figure 1. Slump test result at different super plasticizer dosages.

By increasing the dosage of super plasticizer, the slump loss increases, since the super plasticizer helps to retain the concrete in plastic state for longer time and thus the concrete can be transported for longer distances. However, from the graph, it is seen that over-dosage of super plasticizer leads to very high slump loss, which is undesirable [11]. 


\subsection{Effect of Super Plasticizer on Setting Time of Concrete}

Results for setting time test of concrete with different dosages of superplasticized concrete is shown in the table below. Figures 2 and 3 are the graphs plotted to present the comparison of initial and final setting time of different dosage of the two super plasticizer with the control mix.

Table 3. Concrete Setting Time with SPA and SPB super plasticiers.

\begin{tabular}{lllll}
\hline Dosage & SP AInitial setting time (hrs) & Final setting time (hrs) & SP BInitial setting time (hrs) & Final setting time (hrs) \\
\hline 0.0 & 1.05 & 7.35 & 1.05 & 7.35 \\
1.0 & 3.30 & 8.10 & 2.40 & 8.00 \\
2.0 & 5.10 & 9.30 & 3.45 & 9.10 \\
3.0 & 5.40 & 10.00 & 5.00 & 9.40 \\
4.0 & 7.30 & 10.15 & 5.35 & 10.00 \\
\hline
\end{tabular}

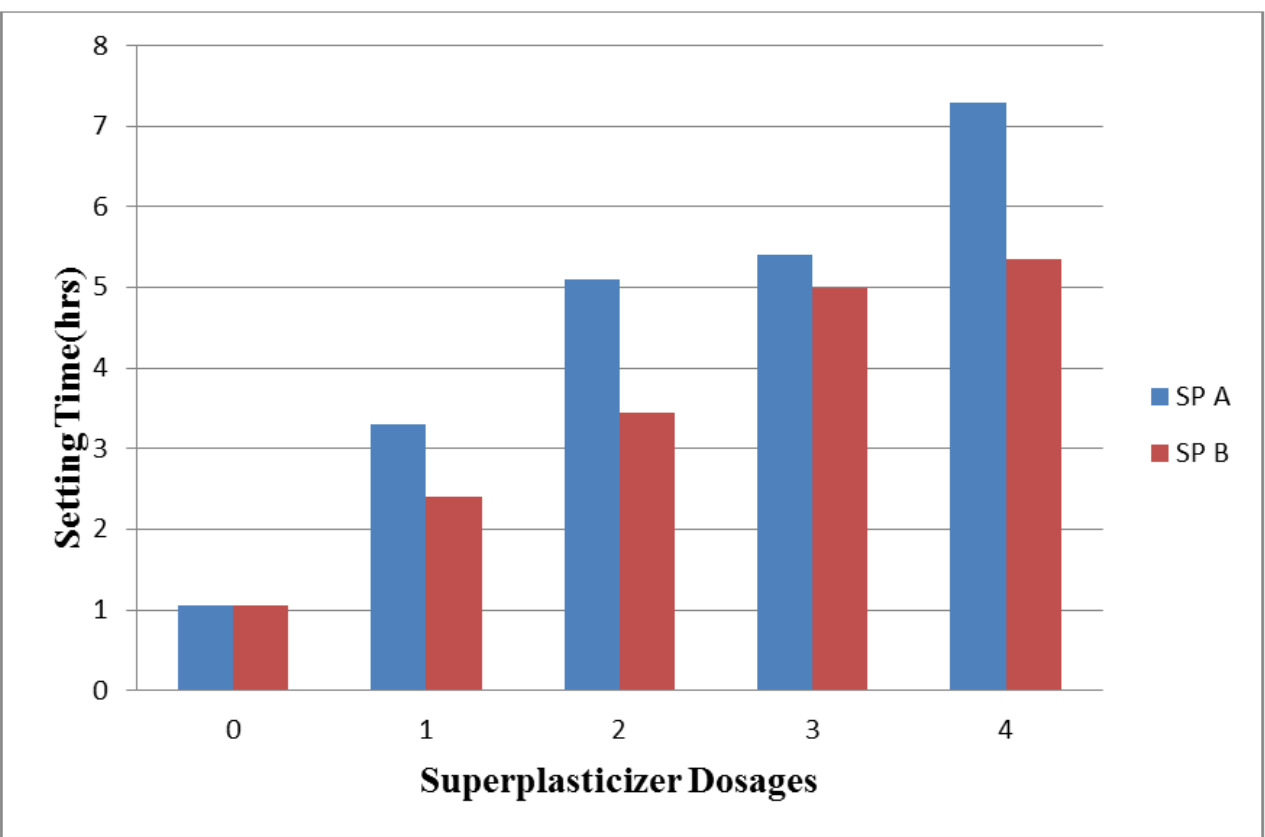

Figure 2. Effect of super plasticizer on initial setting time of concrete.

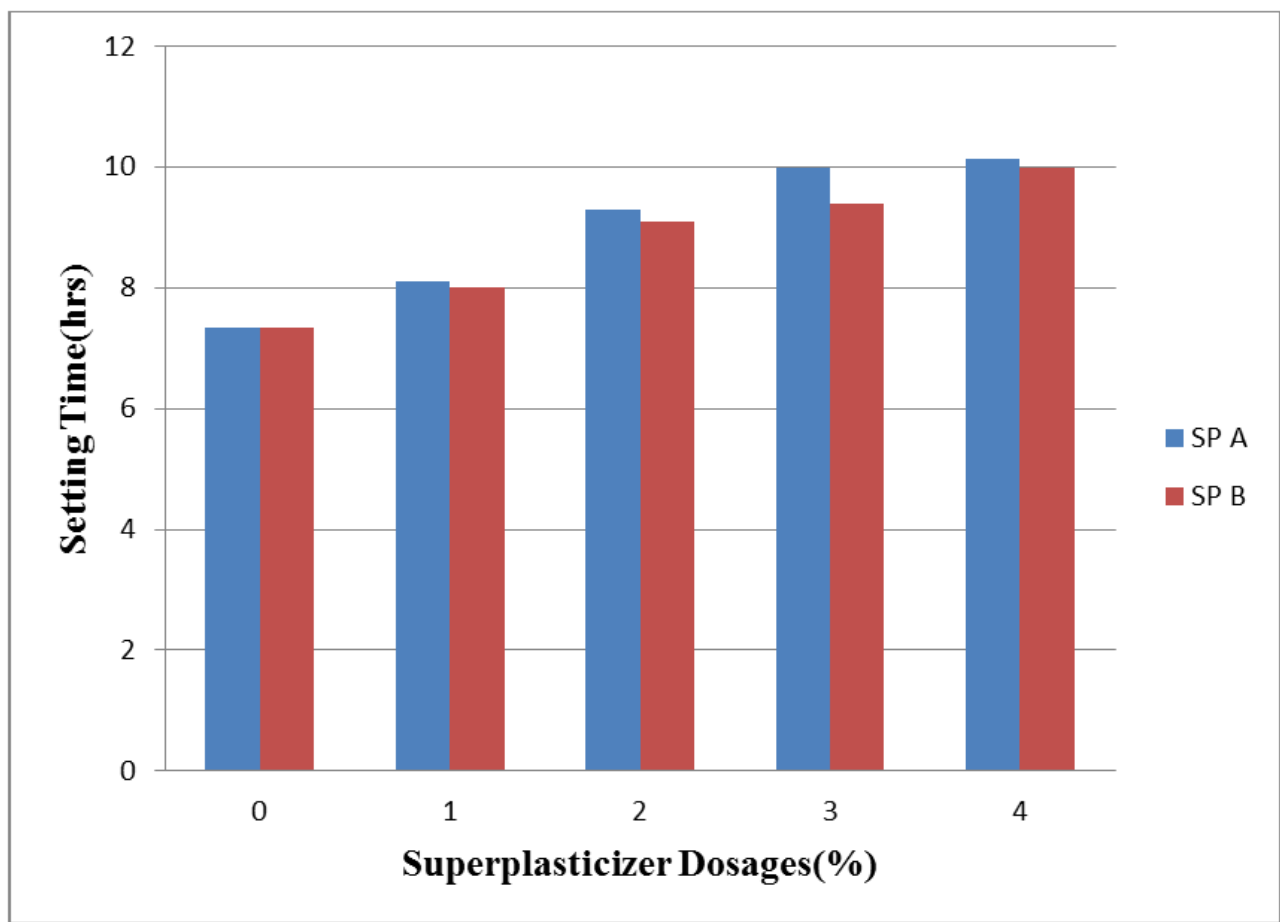

Figure 3. Effect of super plasticizer on final setting time of concrete. 
By observing the graph, there is a significant increase in both the initial and final setting time of concrete when either super plasticizer is added to the concrete. In term of dosage, higher dosage of super plasticizer tends to prolong the setting time. However, different mechanisms are shown by this super plasticizer. However, super plasticizer increases setting time through deflocculating by adsorption of adsorption of negative charges on the cement particles so that they repel each other due to electrostatic force [1].

\subsection{Effect of Super plasticizer on Compressive Strength}

Compressive strength of concrete with different dosage of superplasticizer is shown in table. This test is performed on 7, 14, 21 and 28 days. The values of compressive strength for the different dosage of superplasticizer are then shown as graph in figures 4 and 5.
Table 4. Compressive Strength Test Result for SP A (Conplast 430).

\begin{tabular}{lllll}
\hline Dosage of & \multicolumn{4}{l}{ Compressive Strengths $\left(\mathbf{N} / \mathbf{m m}^{2}\right)$} \\
\cline { 2 - 5 } SP (\%) & 7 Days & 14 Days & 21 Days & 28 Days \\
\hline 0.0 & 18.34 & 19.20 & 23.15 & 25.64 \\
1.0 & 29.31 & 27.73 & 26.43 & 26.79 \\
2.0 & 25.10 & 28.43 & 29.00 & 30.19 \\
3.0 & 24.29 & 27.31 & 28.42 & 29.09 \\
4.0 & 19.07 & 25.71 & 26.43 & 27.11 \\
\hline
\end{tabular}

Table 5. Compressive Strength Test Result for SP B (Dr Fixit).

\begin{tabular}{lllll}
\hline Dosage of & \multicolumn{4}{l}{ Compressive Strengths $\left(\mathbf{N} / \mathbf{m m}^{2}\right)$} \\
\cline { 2 - 5 } SP $(\%)$ & 7 Days & 14 Days & 21 Days & 28 Days \\
\hline 0.0 & 18.34 & 19.20 & 23.15 & 25.64 \\
1.0 & 25.06 & 27.20 & 29.18 & 31.35 \\
2.0 & 24.00 & 26.43 & 28.57 & 34.81 \\
3.0 & 21.48 & 25.31 & 27.17 & 35.21 \\
4.0 & 18.52 & 24.45 & 26.34 & 30.80 \\
\hline
\end{tabular}

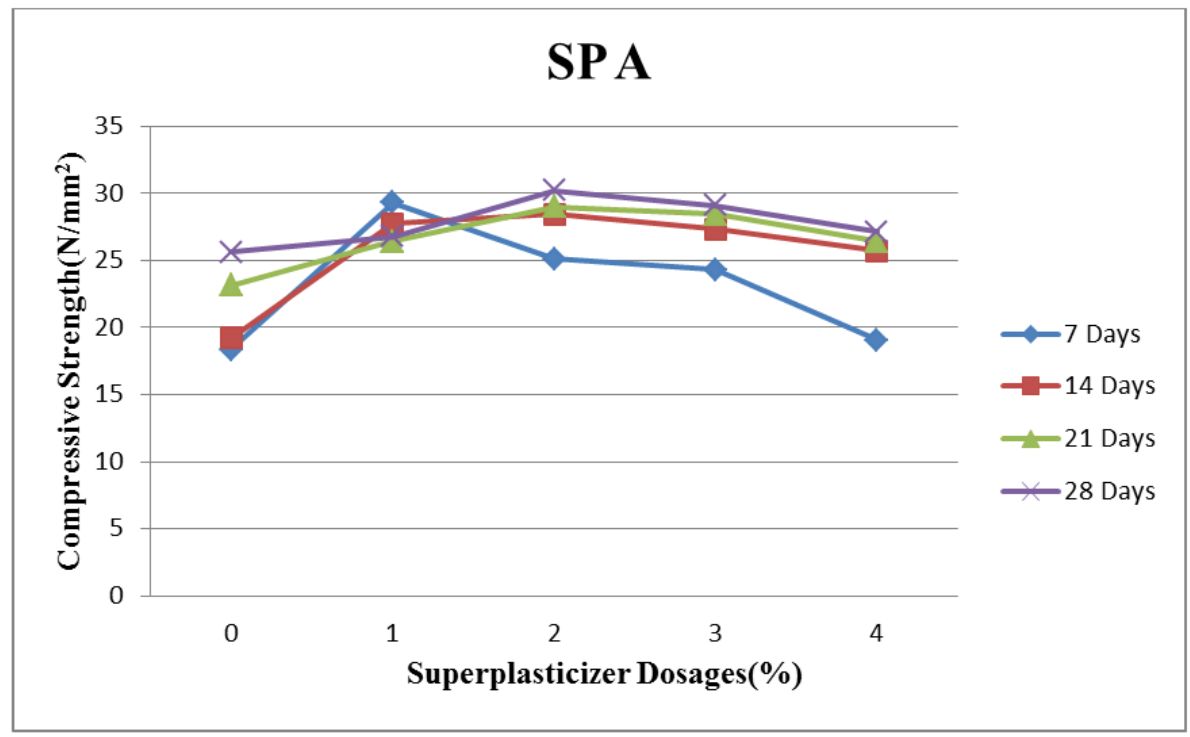

Figure 4. A graph of Compressive strength against Super plasticizer dosages.

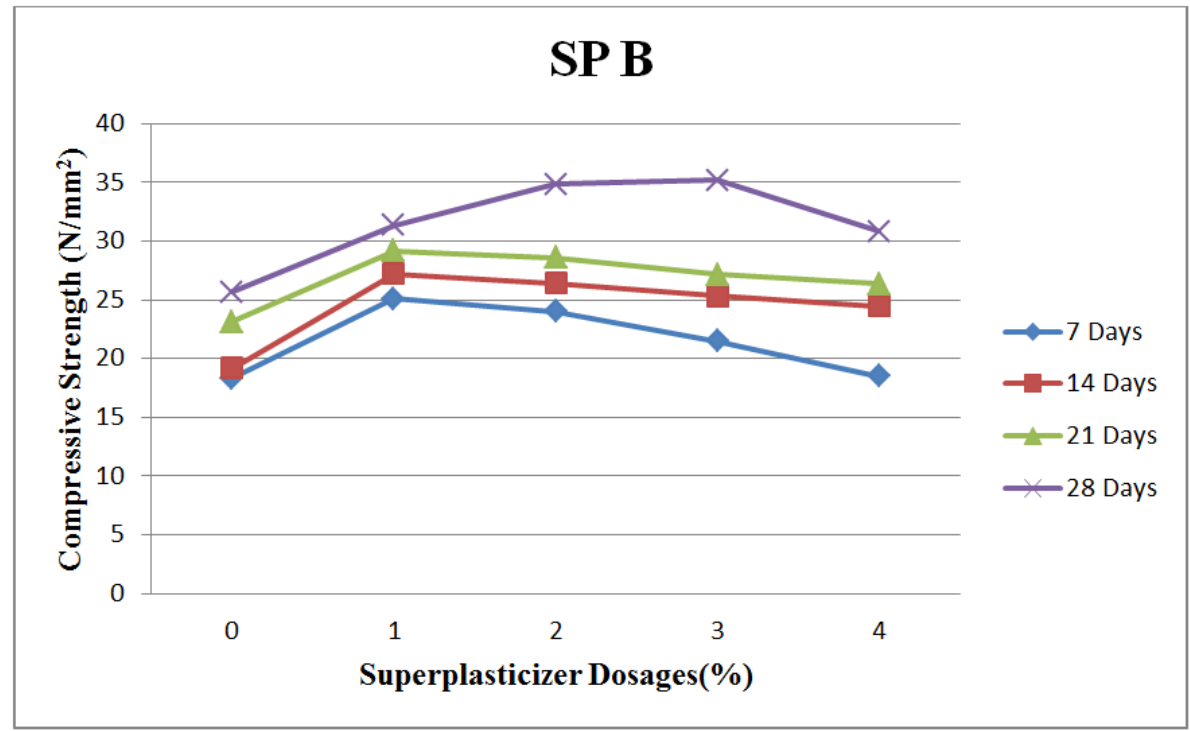

Figure 5. A graph of Compressive strength against Super plasticizer dosages. 
After conducting the experiment, graph of compressive strength versus the super plasticizer dosages is plotted. From the graph, continuous strength gain is observed by the increase in dosage until an optimum limit is reached. When observed, the effect of dosage of the admixture on super plasticized concrete presents different behaviors on the compressive strength of concrete. The increase in dosage will increase the compressive strength for all ages. The effect of Super plasticizers on the compressive strength of concrete is that the compressive strength of concrete is improved by SP addition compared with control [16]. Since addition of SP will provide more water for concrete mixing, not only the hydration process will not be disturbed, but, it is accelerated by the additional water from defloccution of cement particles. Hence, increase in dosage will increase the entrapped water and promote hydration of cement.

Though increment in dosage of super plasticizer will enhance the compressive strength, there is still an optimum limit for the usage of admixture. When the dosages go beyond this limit, increase in dosage will only reduce the compressive strength. This phenomenon occur since over dosage of SP will cause bleeding and segregation, which will affect the cohesiveness and uniformity of the concrete. As a result, compressive strength will reduce if the used dosage is beyond the optimum dosage.[3] The effect of SP dosages on compressive strength of self-compacting concrete concluded that the compressive strength is increased with increase in SP dosage but beyond $2 \%$ the compressive strength decrease with increase in dosage of SP.

\section{Conclusion}

The study aimed at assessing the influence of SP on the Compressive Strength and Setting time of Concrete. Two kinds of SP were used in this research work, therefore their effects on concrete works were compared with similar dosages and similar mix ratio. By analyzing the results of compressive and slump test, the following conclusions are offered;

1. The Ultimate and early strength can be increased by adding super plasticizer. By increasing the dosage of super plasticizer the strength increases. Thus, until the optimum dosage is reached, after that the ultimate and early strength starts decreasing.

2. The workability of concrete increases with the increasing of super plasticizer dosage. However, over dosage of super plasticizer will lead to undesirable workability, which may not be suitable for concrete construction.

3. When the main concern is the early compressive strength, the optimum dosage of SP A (Conplast 430) that can be added to normal concrete is around $1 \%$ while that of SP B (Dr Fixit) is around 1\% also.

4. When the main concern is the ultimate compressive strength, the optimum dosage of SP A (Conplast 430) is $3 \%$ while that of SP B (Dr Fixit) is around 3\%.

\section{References}

[1] Agha-U. C. and Ezeagu C. A. (2016), Experimental Characterization of Mortar Made from local fine aggregate used for Masonry. International Journal of Computational Engineering Research (IJCER) Vol. 6 issue 6 June pp 33-42.

[2] Alsady, S. (2013). Effect of Super plasticizing and Retarding Admixtures on properties of concrete. International conference on innovations in Engineering and Technology, 1 (2), 271-273. Retrieved from http:/dx.doi.org/10.15242/11E.E1213607

[3] Dubey, R., and Kumar, P. (2012). Effect of SP Dosage on Compressive Strength of Self-Compacting Concrete. International Journal of Civil and Structural Engineering, 3 (2), 976-4399.

[4] Ezeagu, C. A, Adinna, B. O, Umenwaliri, S. N. and Umeonyiagu I. E. (2014), "Destructive Effect of Alkali Solution of sodium Hydroxide (caustic soda) to concrete." International Journal of Enterpreneurial Development, Education and science research (IJEDESR) July, vol. 2. No. 1 pp 235-240. Indexed in Google Scholar, worldcat. OCLC: 36144943; EISSN: 1596-6194.

[5] Ezeagu C. A and Ikemefuna C (2019) "Concrete Strength Variations of Washed and Processed Coarse Aggregate Sizes in Alkalinity" East African Scholars Journal of Engineering and Computer Sciences (EASJECS) Vol. 2 Issue 1 Jan. pp 10 -22 .

[6] Garba, M. M. (2014, May). Concreting: Materials, Design, Production and Assembly. Increasing the Core Practice Areas of Builders VI. Paper presented at the 7th annual Mandatory Continuing Professional Development Programme for Builders, Lagos, Nigeria.

[7] Gupta, B. I and Gupta A. (2012). Concrete technology, Standard Publishers Distributors.

[8] Ganiron, T. U. (2013). Influence of Polymer Fibre on Strength of Concrete. International Journal of Advanced Science and Technology, 55 (01), 53-66.

[9] Gambhir, M. L. "Concrete technology", Third edition Tata McGraw- Hill Publishing Company Limited, New Delhi, 2005.

[10] Joseph, A. A and Raymond, M. D (2014) "Rate of Strength Development of Concrete Made Using Selected Nigeria Cement Brands". International Journal of Technology Emerging Engineering Research. Vol. 2 (12) pp. 48-51.

[11] Neville, A. M. and Brooks, J. J. (2010). Concrete Technology. 2nd edition. Pearson education, Longman Group Essex, England.

[12] Nemati, K. M. (2015). Concrete technology: Admixtures in concrete. University of Worshington.

[13] Okampo, A. and Zea, H. (2014). Formulation and Evaluation of Ready Mix Concrete of Chemical Additives Based on Molasses, Carboxymethylcelloluse and Polynaphthalnesulphonate. International Journal of Chemical Technology Research, 6 (01), 769-778. Retrieved from http://www.sphinxsai.com 
[14] Okoro R. I and Ezeagu C. A. (2018) "Concrete Strength Variation of UnWashed and Processed coarse aggregates sizes" American Journal of Scientific Research and essays (AJSRE), 2018, 3; 9 PP 1- 13.

[15] Peurifoy, R. L. (2011). Construction Planning, Equipments and Methods. 8th Edition, McCraw-Hill, New york.
[16] Santhanam, M. (2013). Evaluation of Superplasticizer Performance in Concrete. The 3rd International Conference "Sustainable Constrution Materials and Technologies". 7682. Retrievedfrom http://www.claisse.info/proceedings.htm 